\title{
Research hotspots and trends analysis of ankylosing spondylitis: a bibliometric and scientometric analysis from 2009 to 2018
}

\author{
Miaomiao Liang, Yan Meng, Siming Zhou, Zhengbo Tao, Lin Tao \\ Department of Orthopedics, First Hospital of China Medical University, Shenyang, China \\ Contributions: (I) Conception and design: M Liang, L Tao; (II) Administrative support: L Tao; (III) Provision of study materials or patients: S Zhou; (IV) \\ Collection and assembly of data: Y Meng, S Zhou; (V) Data analysis and interpretation: Y Meng, Z Tao; (VI) Manuscript writing: All authors; (VII) \\ Final approval of manuscript: All authors. \\ Correspondence to: Lin Tao. Department of Orthopedics, First Hospital of China Medical University, 155 Nan Jing North Street, Shenyang 110001, \\ China. Email: taolindr@163.com.
}

\begin{abstract}
Background: This study utilized bibliometric analysis to qualitatively and quantitatively analyze hotspots and predict trends in the field of ankylosing spondylitis (AS) research.

Methods: Articles about AS were obtained from the Web of Science Core Collection and PubMed database, and bibliometric analysis was carried out through CiteSpace and the Online Analysis Platform of Literature Metrology and Bibliographic Item Co-Occurrence Matrix Builder (BICOMB). Then, co-word biclustering analysis was conducted to obtain research hotspots and predict trends using gCLUTO software. Results: A total of 6,818 articles on AS from 2009 to 2018 were analyzed, showing an increasing publication trend (558 articles in 2009 to 851 articles in 2018). The Fournal of Rheumatology was the leading journal in AS research, with an impact factor (IF) of 3.634 and $\mathrm{H}$-index value of 49. In terms of region, the United States led the world in this field, and The University of Toronto was the leading institution for AS research. Van Der Heijde, D was the most prolific author in the field. Eight research hotspots in the field of AS were also identified.
\end{abstract}

Conclusions: Our analysis identified eight research hotspots, and predicted that surgical treatment and etiology will be the main AS research trends in the future. This study provides new directions and ideas for future research in AS.

Keywords: Ankylosing spondylitis (AS); bibliometric analysis; co-word analysis; biclustering; hotspots

Submitted Feb 03, 2020. Accepted for publication Aug 21, 2020.

doi: $10.21037 / \mathrm{atm}-20-1259$

View this article at: http://dx.doi.org/10.21037/atm-20-1259

\section{Introduction}

Ankylosing spondylitis (AS) is an immune-mediated chronic disease, and one of the most common arthropathic diseases. It mainly affects the axial skeleton, causing spinal structural damage, which can lead to back pain, stiffness, and limited lumbar movement. Disease onset typically occurs after the age of 30 , and the disease mainly affects males, with an incidence approximately 2-3 times that of women $(1,2)$. In recent years, however, due to AS attracting more attention and diagnostic improvements, a larger number of children aged 6-10 years are also being diagnosed. Due to this younger age of onset, understanding AS is particularly important and urgent. While the pathophysiology of AS is not yet fully understood, studies on twins have shown that the disease is more than $90 \%$ hereditary (3). HLA-B27 expression is also closely correlated with AS, but its role in AS onset is not yet clear.

The main treatment approach in AS is medication, including anti-TNF agents and non-steroidal antiinflammatory drugs (NSAIDS). The interleukin-17 inhibitor secukinumab also has demonstrated efficacy in the management of AS (4). However, the efficacy, correct dosage, and safety of various drugs have yet to be fully 
investigated. In recent years, surgical treatment has also garnered more attention, but the choice of specific surgical methods and treatment efficacy remain controversial. Currently, no standard treatment for AS exists, and the current research trends in the field are not well defined. Hence, summarizing research trends is important for future researchers' understanding of AS, and in helping to identify where to focus research efforts to best help AS patients. Therefore, this study investigated research hotspots to help future researchers fill in the knowledge gaps in the field of AS.

Bibliometrics is a widely used methodology which uses statistical methods to analyze the quality of research, and to reveal research hotspots and research trends in a specific topic area. It also utilizes statistical indexes to evaluate the contribution of scientific publications in a particular research area. Bibliometrics uses statistical analysis including cluster analysis and factor analysis to define research hotspots and the structure of the subject, then classify the keywords of the topic. Cluster analysis is the most commonly used method. Different from traditional clustering, biclustering not only processes the global information but also allows the rows and columns of the matrix to be processed simultaneously so that it can detect local messages more efficiently when encountering high-dimensional data. Biclustering analysis has been widely utilized in recent years in the area of bibliometrics. Through biclustering, Yan et al. discovered the cytokine clusters associated with the prognosis of chronic lymphocytic leukemia (5). The miRNA expression profiles of breast cancer were also revealed by researchers using biclustering (6). We also previously predicted the research hotspots in postmenopausal osteoporosis through the biclustering method (7). These previous studies demonstrate that the biclustering analysis method can effectively reveal the hotspots of research and provide direction for future AS research.

Currently, few bibliometric studies on AS exist. In this study, we analyzed relevant publications between 2009 and 2018 to ascertain the current research situation and progress in AS. Furthermore, we adopted a co-word biclustering analysis method to clarify research hotspots in AS. It is hoped that this study will provide new directions and ideas for future research in AS.

\section{Methods}

\section{Data source and search strategy}

Literature about AS was extracted from the Social Science
Citation Index and the Science Citation Index-Expanded from the Web of Science Core Collection (WoSCC) on December 2, 2019. The search terms "Spondylitis, Ankylosing AND Language = English", were used, with a time limitation between January 1st, 2009 and December 31st, 2018. Original articles and reviews in English were the only publication types collected. PubMed was also used, as MeSH (Medical Subject Headings) terms were able to represent the subject of the articles and enabled us to carry out continuous co-word clustering analysis (8). Additionally, to prevent inaccuracies caused by data updates, all data were collected on the same day.

\section{Data collection}

Two researchers independently screened the search results with a consensus rating of 0.9. Any differences were discussed to reach an agreement. Data in text format were converted from the WoSCC data and imported into CiteSpace 5.7.R1, 64bit (Drexel University, Philadelphia, PA, USA) and the Online Analysis Platform of Literature Metrology (http:// bibliometric.com/) for bibliometric analysis. Each article downloaded from PubMed was imported in XML format into Bibliographic Item Co-Occurrence Matrix Builder (BICOMB) for the following hotspot analyses (9).

\section{Data analysis}

\section{Bibliometric analysis}

The characteristics of the retrieved articles were summarized, including author details, institution, journal, country, citations, $\mathrm{H}$ index, and annual publications. We also evaluated the impact factors (IF) and citations obtained from fournal Citation Reports (FCR) 2018, and then collected the characteristics of the publication's reputation and influence. The annual publication numbers and growth trends were analyzed using the Literature Metrology online analysis platform. CiteSpace was used to connect authors, institutions, journals, countries, and other factors into a network for analysis. CiteSpace also facilitated the extraction of a certain number of papers within a specified number of years into a single network through the "timeslicing" function. We chose different node types, and the number of publications and citations were represented by their sizes $(10,11)$.

\section{Co-word biclustering analysis}

Major MeSH terms/MeSH subheading terms were 


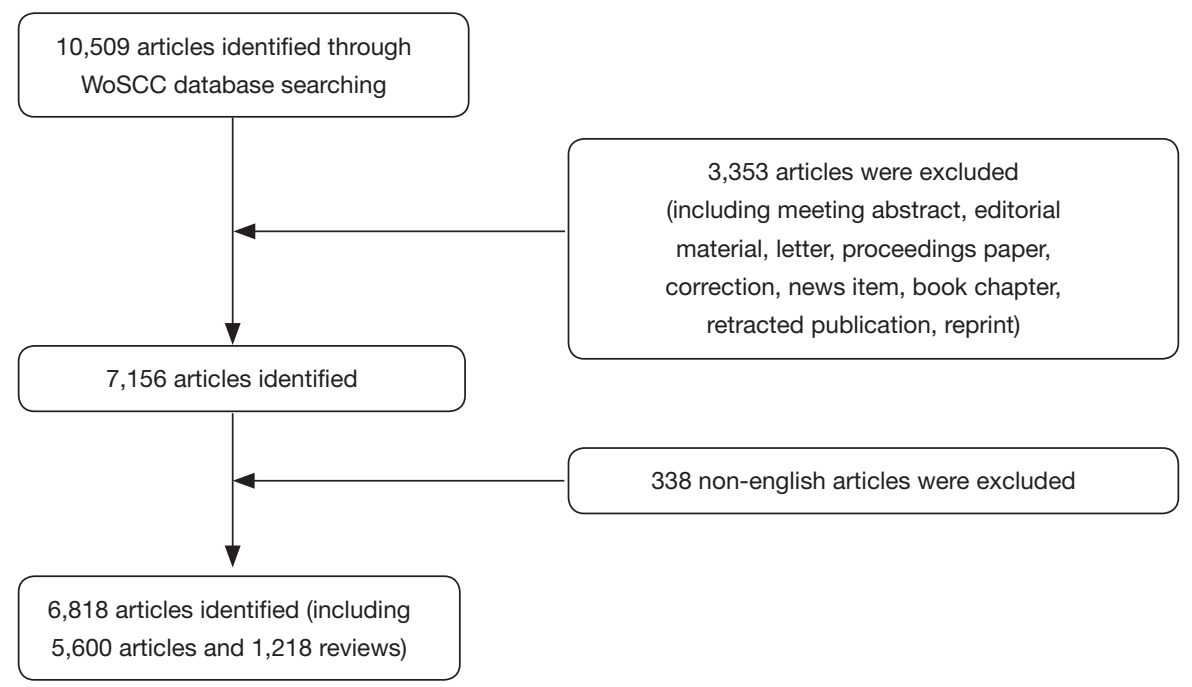

Figure 1 Flow chart of literature filtering performed in this study.

analyzed with BICOMB and Microsoft Excel, and their frequency permutations in proportion to the related literature were determined. The $\mathrm{MeSH}$ terms that occurred at high frequencies were analyzed, and the trends were determined. A biclustering analysis of these terms was also carried out, and publications were selected to determine the research hotspots of AS. Biclustering was used to reveal the relationship between source articles and high-frequency terms, and the relationship between high-frequency terms. We used the high-frequency terms as rows and the source articles as columns. gCLUTO 1.0 (Graphical CLUstering Toolkit) software developed by Rasmussen et al. was used to construct a binary matrix for biclustering analysis (12). Parameters suitable for biclustering analysis in gCLUTO were set according to the literature. $\mathrm{I}^{2}$ was determined as a standard function, and Cosine as a similarity function. The clustering method was repeated in bisects. The results of the biclustering analyses were presented in the form of a mountain visualization and matrix visualization. We redirected biclustering with various cluster numbers until the optimal matrix visualization and mountain visualization results were obtained. We then also mapped and established the basic structure of our research based on the semantic relationship between the terms and the typical source articles.

Ethical approval is not required because the research didn't involve human experiments.

\section{Results}

Distribution characteristics of literature

\section{Obtaining relevant literature}

According to our search strategy, our study generated a total of 6,818 English publications from 2009 to 2018, including 5,600 articles and 1,218 reviews. The literature screening strategy is shown in Figure 1. Figure 2 shows the number and trends of AS-related publications over the past 10 years. The overall literature was found to be increasing, from 558 in 2009 to 851 in 2018.

\section{Distribution characteristics of countries/regions and institutions}

According to the preliminary statistics, articles about AS by active authors came from at least 89 countries, and the top 10 countries that contributed articles are listed in Figure 3. In the decade between 2009 and 2018, the United States $[1,249]$ was the largest contributor to AS research, followed by China [1,091], the United Kingdom [666], Germany [608], and the Netherlands [605]. The most significant influence on other countries was Spain, with a centrality of 0.11, followed by France and Canada (both centrality $=0.08$ ) (Table 1). The top 10 institutions for AS research output included the University of Toronto [322], Leiden University [283], Charite [226], University of Alberta 


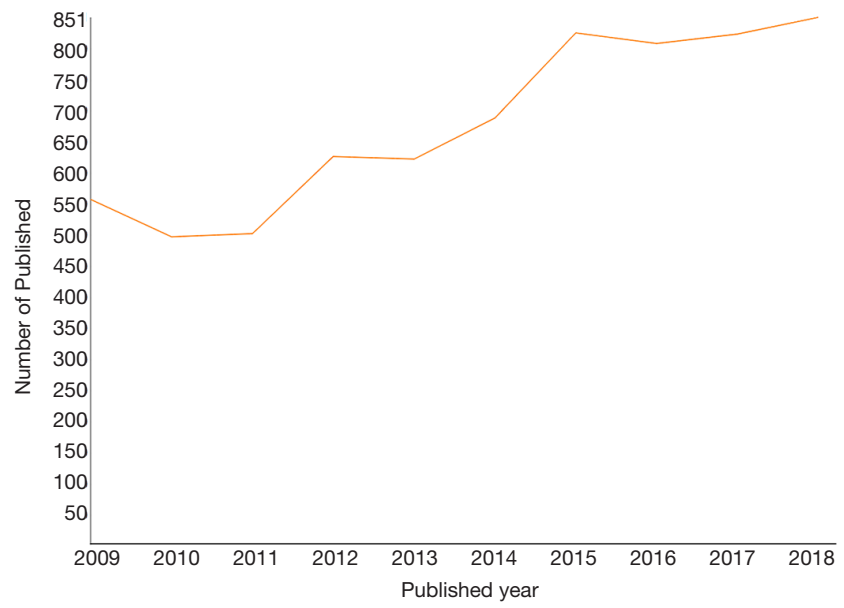

Figure 2 Output of related literature. The number of annual publications in the field of AS from 2009 to 2018.

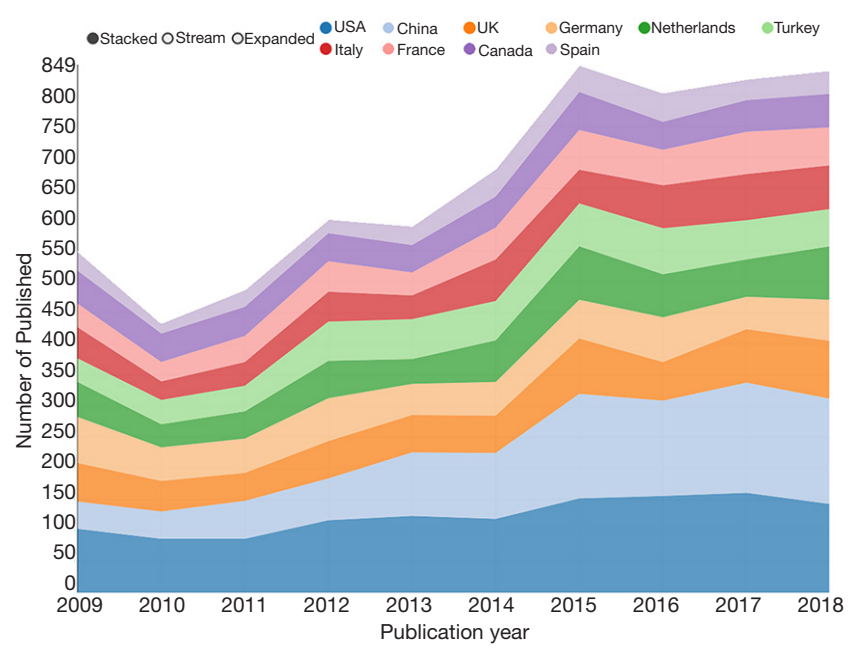

Figure 3 Output of related literature. The growth trends of the top 10 countries/regions in AS research from 2009 to 2018.

[194], and Oregon Health \& Science University [176] (Figure 3). Figure 4 shows the AS research network, with a density of 0.0609 , which is a low-density map, indicating that the research groups are relatively scattered and the institutions do not closely collaborate. Among the top 10 institutions for AS scientific research output (Table 1), almost all of the central indexes were lower than 0.15 (except the University of Alberta), suggesting that most institutions have low influence and less inter-agency cooperation. Figure 5 shows the international cooperative relationships. The United States and Canada cooperated most frequently, followed closely by the United States and Germany.

\section{Fournal distribution}

There was a total of 1,076 journals in the AS field. Of the 6,818 publications retrieved, the output of the top 10 most active ASrelated journals accounted for $35.12 \%$ of them, with a total of 2,395. Table 2 ranks the top 10 most active journals. The fournal of Rheumatology, Clinical Rheumatology, and Annals of The Rheumatic Diseases ranked as the top three. These three journals accounted for $15.20 \%$ of all retrieved articles in the field. The journal with the highest IF was Annals of The Rheumatic Diseases, with IF 14.299, followed by RHEUMATOLOGY (5.149), Artbritis Care \& Research (4.53), Arthritis Research \& Therapy (4.148), and Fournal of Rheumatology (3.634). According to the $\mathcal{F C R} 2018$ standard, these 10 most active journals were spread across Q1, Q2, and Q3 partitions.

\section{Autbor distribution}

A total of 21,639 authors were involved in the AS studies retrieved. The top 10 authors were listed in order of the number of outputs. The most prolific researchers were: van der Heijde D, Sieper J, Braun J, Dougados M, Maksymowych WP, Inman RD, Landewe R, Baraliakos X, Brown MA, and Rudwaleit M (Table 3). Among them, van der Heijde D, from the Leiden University Medical Center, The Netherlands, ranked first with 208 articles, followed by Sieper from the Department of Gastroenterology, Infectious Diseases and Rheumatology, Campus Benjamin Franklin, CharitéUniversitätsmedizin Berlin, Germany, with 182 articles. These two researchers have made significant contributions and have strong influence and authority in the field of AS research. CiteSpace was used to analyze the information of authors and co-cited authors, and to plot a visual network (Figures 6,7). The highest co-cited author is Braun J, with 2,119 co-citations, followed by Vanderlinden S [1,918], Rudwaleit M [1,522], and Van Der Heijde D [1,489]. The centrality indexes of Braun J, Rudwaleit M, Van Der Heijde $\mathrm{D}$, Calin A were all greater than 0.1 , indicating that they had a significant influence in the field of AS research.

\section{Research hotspots in AS}

A total of 4,493 major MeSH terms/MeSH subheading terms were obtained from the literature. The cumulative calculation frequency was 18,459 . We defined terms that occurred more than 48 times after the evaluation of the $\mathrm{H}$ 
Table 1 The top 10 countries/regions and institutions contributing to publications in ankylosing spondylitis (AS) research

\begin{tabular}{|c|c|c|c|c|c|c|c|c|c|c|c|}
\hline Rank & $\begin{array}{l}\text { Country/ } \\
\text { region }\end{array}$ & $\begin{array}{l}\text { Article } \\
\text { counts }\end{array}$ & Centrality & Institutions & $\begin{array}{l}\text { Article } \\
\text { counts }\end{array}$ & Centrality & $\begin{array}{l}\text { Total } \\
\text { number of } \\
\text { citations }\end{array}$ & $\begin{array}{l}\text { Average } \\
\text { number of } \\
\text { citations }\end{array}$ & $\begin{array}{l}\text { Total } \\
\text { number of } \\
\text { first authors }\end{array}$ & $\begin{array}{l}\text { Total } \\
\text { number of } \\
\text { first author } \\
\text { citations }\end{array}$ & $\begin{array}{l}\text { Average } \\
\text { number of } \\
\text { first author } \\
\text { citations }\end{array}$ \\
\hline 1 & USA & 1249 & 0.05 & Univ Toronto & 322 & 0.07 & 4,364 & 13.55 & 62 & 570 & 9.19 \\
\hline 2 & China & 1091 & 0.00 & Leiden Univ & 283 & 0.13 & 7,502 & 26.51 & 84 & 1479 & 17.61 \\
\hline 4 & Germany & 608 & 0.03 & Univ Alberta & 194 & 0.16 & 6,514 & 33.58 & 60 & 1046 & 17.43 \\
\hline 5 & $\begin{array}{l}\text { The } \\
\text { Netherlands }\end{array}$ & 605 & 0.01 & $\begin{array}{l}\text { Oregon Hith } \\
\text { \& Sci Univ }\end{array}$ & 176 & 0.03 & 2,354 & 13.38 & 53 & 410 & 7.74 \\
\hline 6 & Turkey & 580 & 0.00 & $\begin{array}{l}\text { Univ Tehran } \\
\text { Med Sci }\end{array}$ & 162 & 0.00 & 723 & 4.46 & 50 & 197 & 3.94 \\
\hline 8 & France & 498 & 0.08 & $\begin{array}{l}\text { Paris } \\
\text { Descartes } \\
\text { Univ }\end{array}$ & 154 & 0.03 & 2,072 & 13.45 & 45 & 478 & 10.62 \\
\hline 9 & Canada & 496 & 0.08 & $\begin{array}{l}\text { Univ } \\
\text { Amsterdam }\end{array}$ & 150 & 0.09 & 3,146 & 20.97 & 50 & 880 & 17.6 \\
\hline 10 & Spain & 339 & 0.11 & Univ Oxford & 147 & 0.05 & 3,193 & 21.72 & 52 & 859 & 16.52 \\
\hline
\end{tabular}

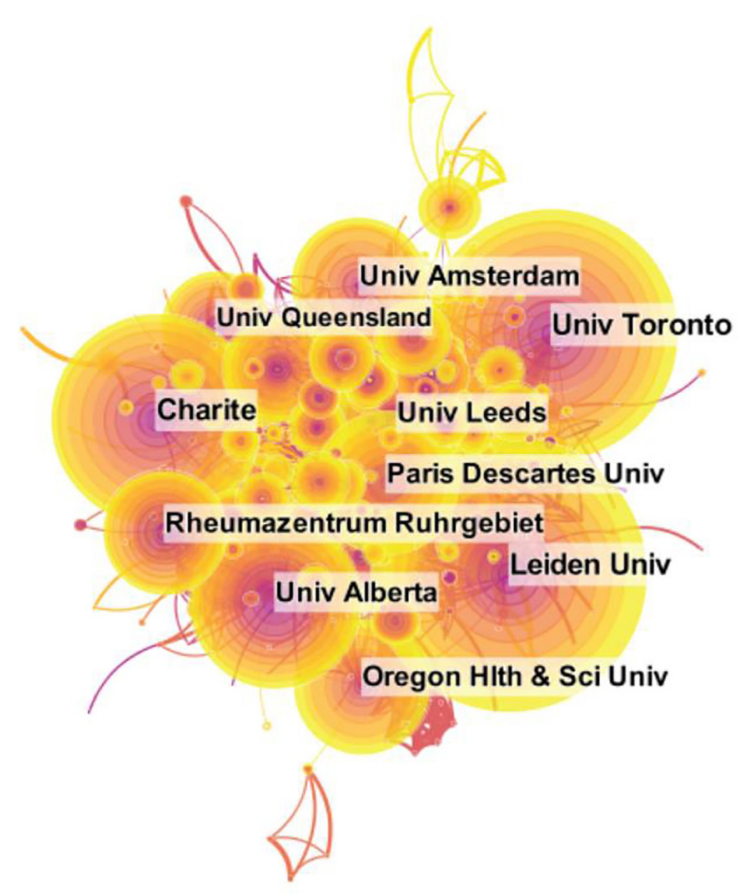

Figure 4 The distribution of countries/regions and institutions. The network map of institutions that are actively involved in AS research within countries/regions. AS, ankylosing spondylitis. index standard as extremely frequent terms. Table 4 lists 47 extremely frequent terms extracted from the retrieved literature. The cumulative percentage was $40.37 \%$ $(7,452 / 18,459)$. Table 5 shows the extremely frequent major $\mathrm{MeSH}$ terms/MeSH subheading terms-source articles matrix. gCLUTO was used to reset the rows of the initial matrix to aggregate similar rows in the same cluster so that 47 terms were divided into 8 clusters with biclustering, and each cluster showed the main terms contained in the source articles. We analyzed the typical articles in each cluster and summarized the topics of each cluster as follows:

- Surgical treatment of AS (Cluster 0);

* Anti-TNF inhibitor treatment for AS (Cluster 1);

* Correlation between endoplasmic reticulum aminopeptidase 1 (ERAP1) polymorphism and AS (Cluster 2);

* MRI diagnosis for AS (Cluster 3);

* HLA-B27 pathogenesis of AS (Cluster 4);

* Certain TNF inhibitors as a first-line treatment of AS, and their efficacy and safety (Cluster 5);

* Early diagnosis and therapy of AS (Cluster 6);

* Rehabilitation treatment of AS (Cluster 7).

* The biclustering results are presented in the form 


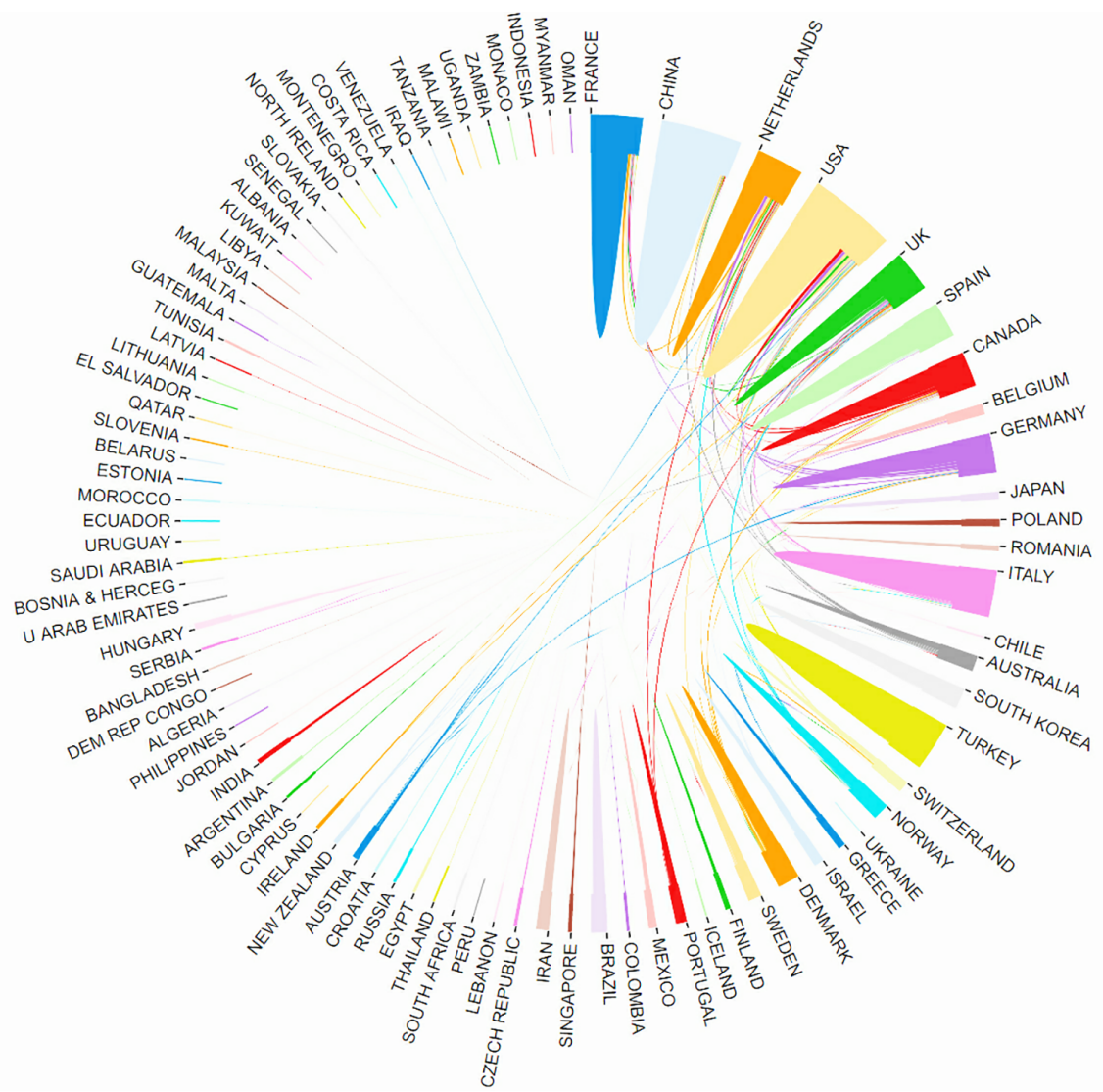

Figure 5 The distribution of countries/regions and institutions. The cooperation of countries/regions.

Table 2 The top 10 most active journals that published articles in ankylosing spondylitis (AS) research (sorted by count)

\begin{tabular}{|c|c|c|c|c|c|c|c|c|}
\hline Rank & Journal title & Article counts & $\begin{array}{l}\text { Percentage } \\
(\mathrm{N} / 6,818)\end{array}$ & IF [2018] & $\begin{array}{l}\text { Quartile in } \\
\text { category [2018] }\end{array}$ & $\mathrm{H}$-index & $\begin{array}{l}\text { Total number } \\
\text { of citations }\end{array}$ & $\begin{array}{l}\text { Average number } \\
\text { of citations }\end{array}$ \\
\hline 1 & $\begin{array}{l}\text { Journal of } \\
\text { Rheumatology }\end{array}$ & 360 & 0.052801408 & 3.634 & Q2 & 49 & 3,242 & 9.01 \\
\hline 2 & $\begin{array}{l}\text { Clinical } \\
\text { Rheumatology }\end{array}$ & 345 & 0.050601349 & 2.293 & Q3 & 39 & 1,594 & 4.62 \\
\hline 3 & $\begin{array}{l}\text { Annals of the } \\
\text { Rheumatic Diseases }\end{array}$ & 332 & 0.048694632 & 14.299 & Q1 & 121 & 12,119 & 36.5 \\
\hline 4 & $\begin{array}{l}\text { Rheumatology } \\
\text { International }\end{array}$ & 306 & 0.044881197 & 2.2 & Q3 & 35 & 1,608 & 5.25 \\
\hline 5 & $\begin{array}{l}\text { Clinical and } \\
\text { Experimental } \\
\text { Rheumatology }\end{array}$ & 266 & 0.039014374 & 3.238 & Q2 & 43 & 1,615 & 6.07 \\
\hline 8 & $\begin{array}{l}\text { Arthritis Care \& } \\
\text { Research }\end{array}$ & 129 & 0.018920505 & 4.53 & Q2 & 56 & 1,338 & 10.37 \\
\hline 9 & PLoS One & 115 & 0.016867116 & 2.776 & Q2 & 176 & 445 & 3.87 \\
\hline 10 & Joint Bone Spine & 113 & 0.016573775 & 3.278 & Q2 & 34 & 762 & 6.74 \\
\hline
\end{tabular}




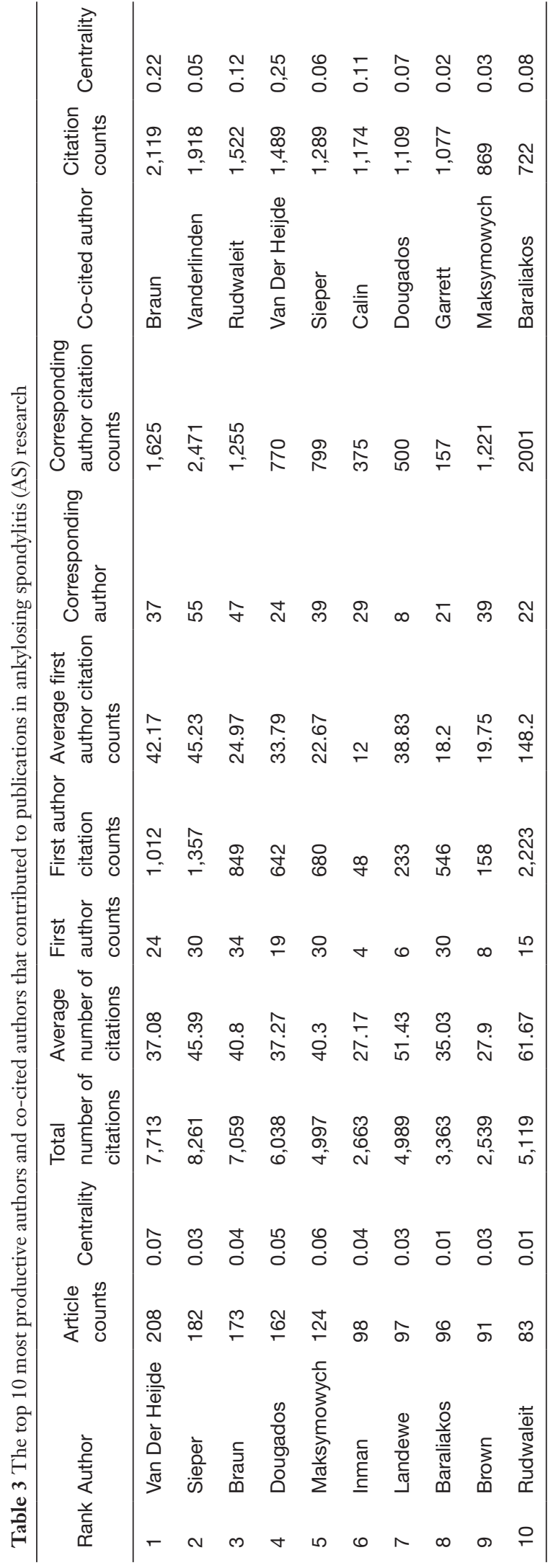

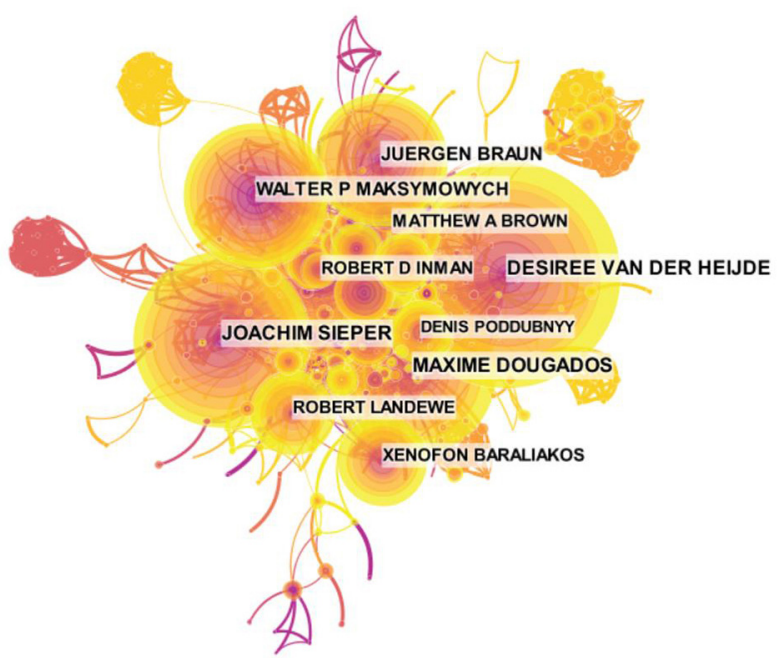

Figure 6 The distribution of authors engaged in AS research. The network map of productive authors. AS, ankylosing spondylitis.

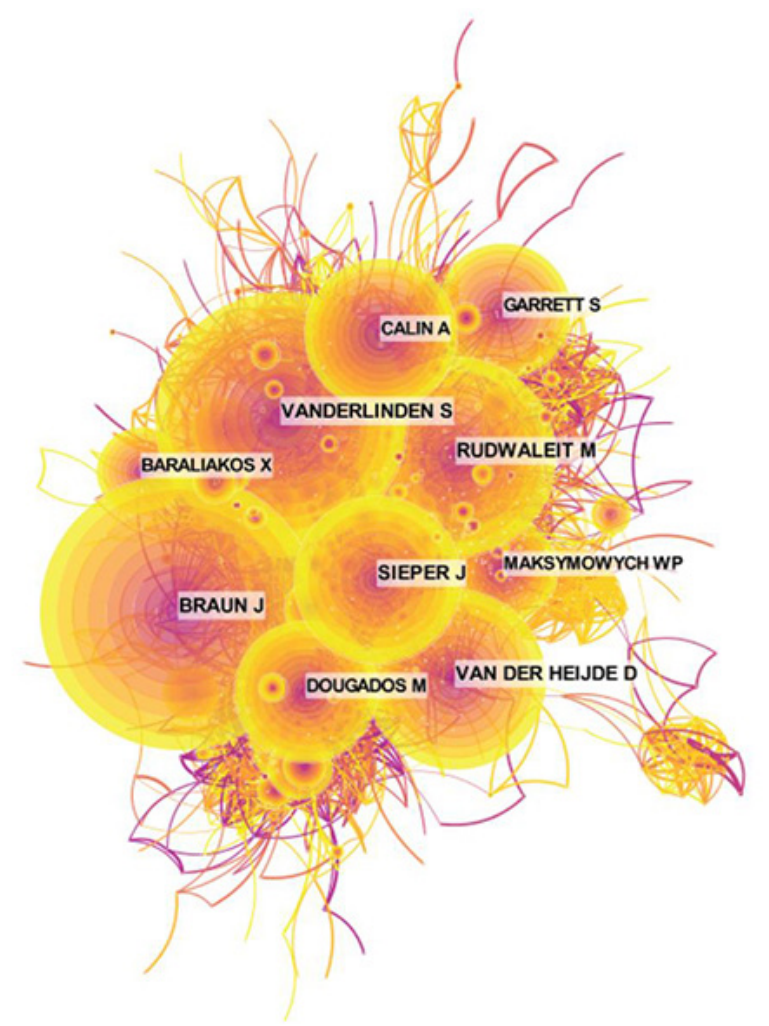

Figure 7 The distribution of authors engaged in AS research. The network map of co-cited authors. AS, ankylosing spondylitis. 
Table 4 High-frequency major MeSH terms from the included publications on ankylosing spondylitis (AS) $(\mathrm{n}=18,459)$

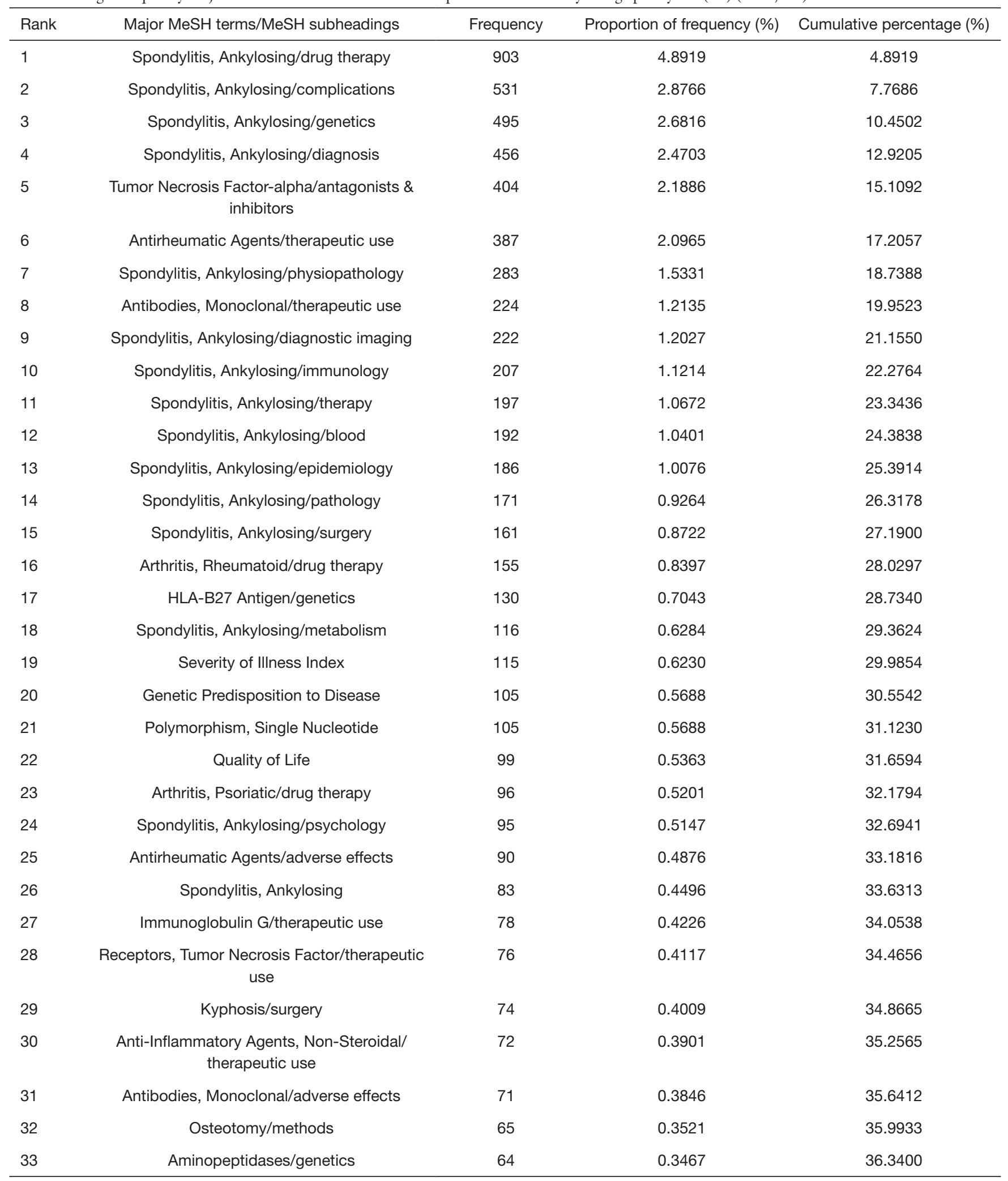

Table 4 (continued) 
Table 4 (continued)

\begin{tabular}{|c|c|c|c|c|}
\hline Rank & Major MeSH terms/MeSH subheadings & Frequency & Proportion of frequency (\%) & Cumulative percentage (\%) \\
\hline 35 & Spondylarthritis/drug therapy & 59 & 0.3196 & 36.9901 \\
\hline 36 & Disability Evaluation & 57 & 0.3088 & 37.2989 \\
\hline 37 & Anti-Inflammatory Agents/therapeutic use & 57 & 0.3088 & 37.6077 \\
\hline 39 & Spine/diagnostic imaging & 55 & 0.2980 & 38.2036 \\
\hline 40 & Sacroiliac Joint/pathology & 54 & 0.2925 & 38.4961 \\
\hline 41 & Antirheumatic Agents/administration \& dosage & 53 & 0.2871 & 38.7832 \\
\hline 42 & Magnetic Resonance Imaging/methods & 50 & 0.2709 & 39.0541 \\
\hline 45 & Asian Continental Ancestry Group/genetics & 49 & 0.2655 & 39.8505 \\
\hline 46 & Biological Products/therapeutic use & 48 & 0.2600 & 40.1105 \\
\hline 47 & Polymorphism, Genetic & 48 & 0.2600 & 40.3706 \\
\hline
\end{tabular}

Table 5 High-frequency major MeSH in a terms-source articles matrix (localized)

\begin{tabular}{|c|c|c|c|c|c|c|}
\hline No. & $\begin{array}{l}\text { Major MeSH terms/MeSH } \\
\text { subheadings }\end{array}$ & \multicolumn{5}{|c|}{ PubMed Unique Identifiers of source articles } \\
\hline 1 & $\begin{array}{c}\text { Spondylitis, Ankylosing/drug } \\
\text { therapy }\end{array}$ & 1 & 0 & 1 & $\ldots$ & 0 \\
\hline 2 & $\begin{array}{l}\text { Spondylitis, Ankylosing/ } \\
\text { complications }\end{array}$ & 0 & 0 & 0 & $\ldots$ & 0 \\
\hline 4 & $\begin{array}{l}\text { Spondylitis, Ankylosing/ } \\
\text { diagnosis }\end{array}$ & 0 & 0 & 0 & $\cdots$ & 0 \\
\hline$\cdots$ & $\cdots$ & $\cdots$ & $\cdots$ & $\cdots$ & $\cdots$ & $\cdots$ \\
\hline 47 & Polymorphism, Genetic & 0 & 0 & 0 & $\ldots$ & 0 \\
\hline
\end{tabular}



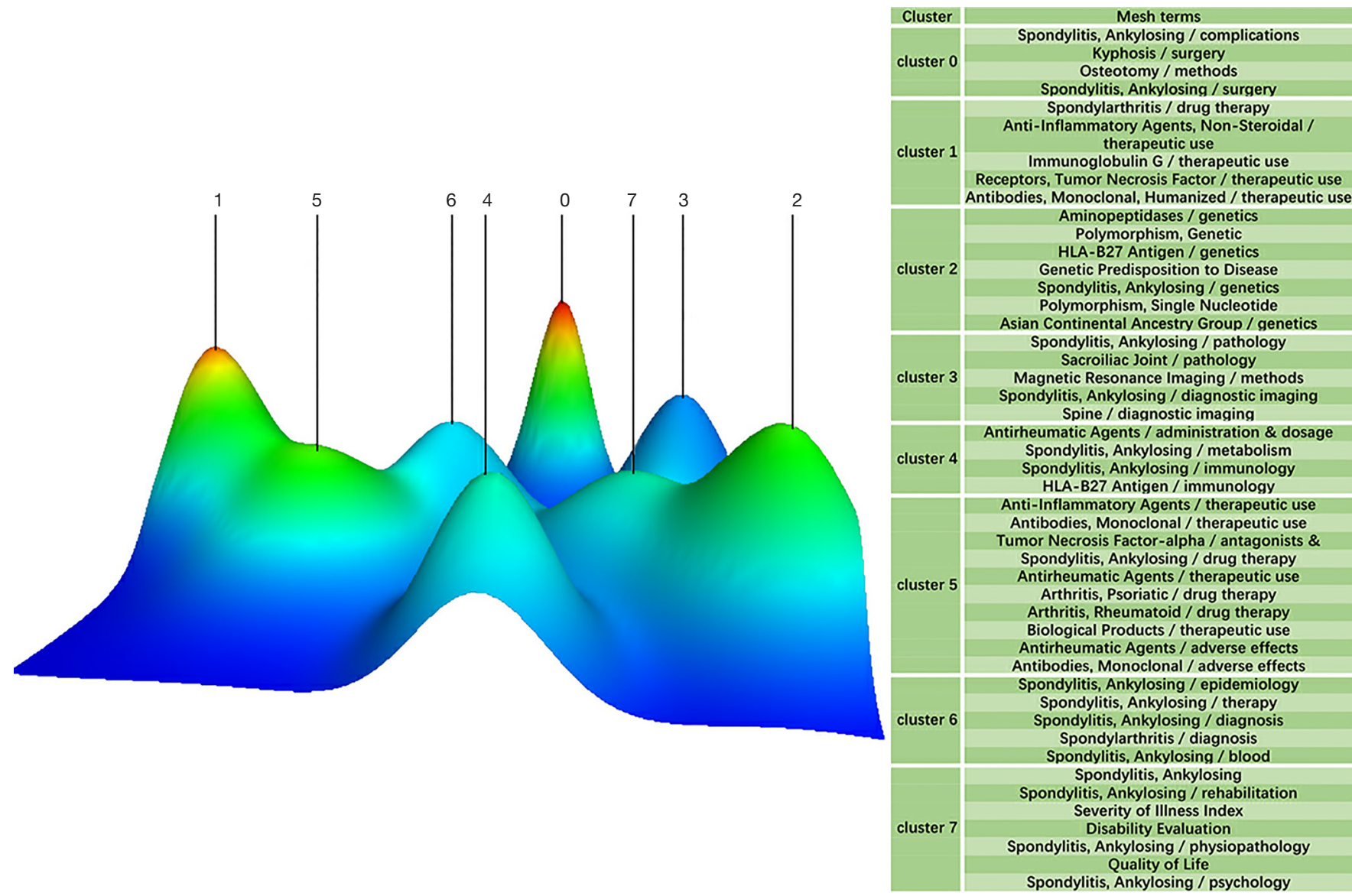

Figure 8 Mountain visualization depicting biclustering of high-frequency major MeSH terms and literature on AS. AS, ankylosing spondylitis.

of mountain visualization (Figure 8 ) and matrix visualization (Figure 9).

The mountain visualization in Figure 8 shows the 8 clusters from 0 to 7 after biclustering and the extremely frequent terms contained in each cluster. The biclustering results and the nature of the high-dimensional datasets can be intuitively expressed through mountain visualization. In Figure 8, each peak represents a different cluster. The position, height, color, and volume of the peaks on the plane can reflect the information of the clusters, of which the position of the peaks on the plane is most significant when compared with other peaks. The interval between the peaks can indicate the relative similarity of the clusters. The height of the peak often represents the internal similarity in the cluster. The color of the peak shows the internal standard deviation of the objects in each cluster: blue indicates a high deviation, and red indicates a low deviation. The volume of each peak is proportional to the number of extremely frequent terms stored in the cluster. There was a minimum of 30 publications per cluster. We ruled out results with three-peaked peaks.

Figure 9 shows the matrix visualization, with extremely frequent major $\mathrm{MeSH}$ terms/MeSH subheading terms as row labels and the PMIDs of the source articles as the column labels. The color depth of the blocks which were proportional to the frequency of the terms in the articles represented the values; the darker the color, the greater the significance. White means almost no significance. The relationships between the source articles are shown in the cluster tree above. The relationships among extremely frequent major $\mathrm{MeSH}$ terms/MeSH subheading terms are shown in the cluster tree on the left.

\section{Discussion}

As the incidence of orthopedic diseases increases year by 


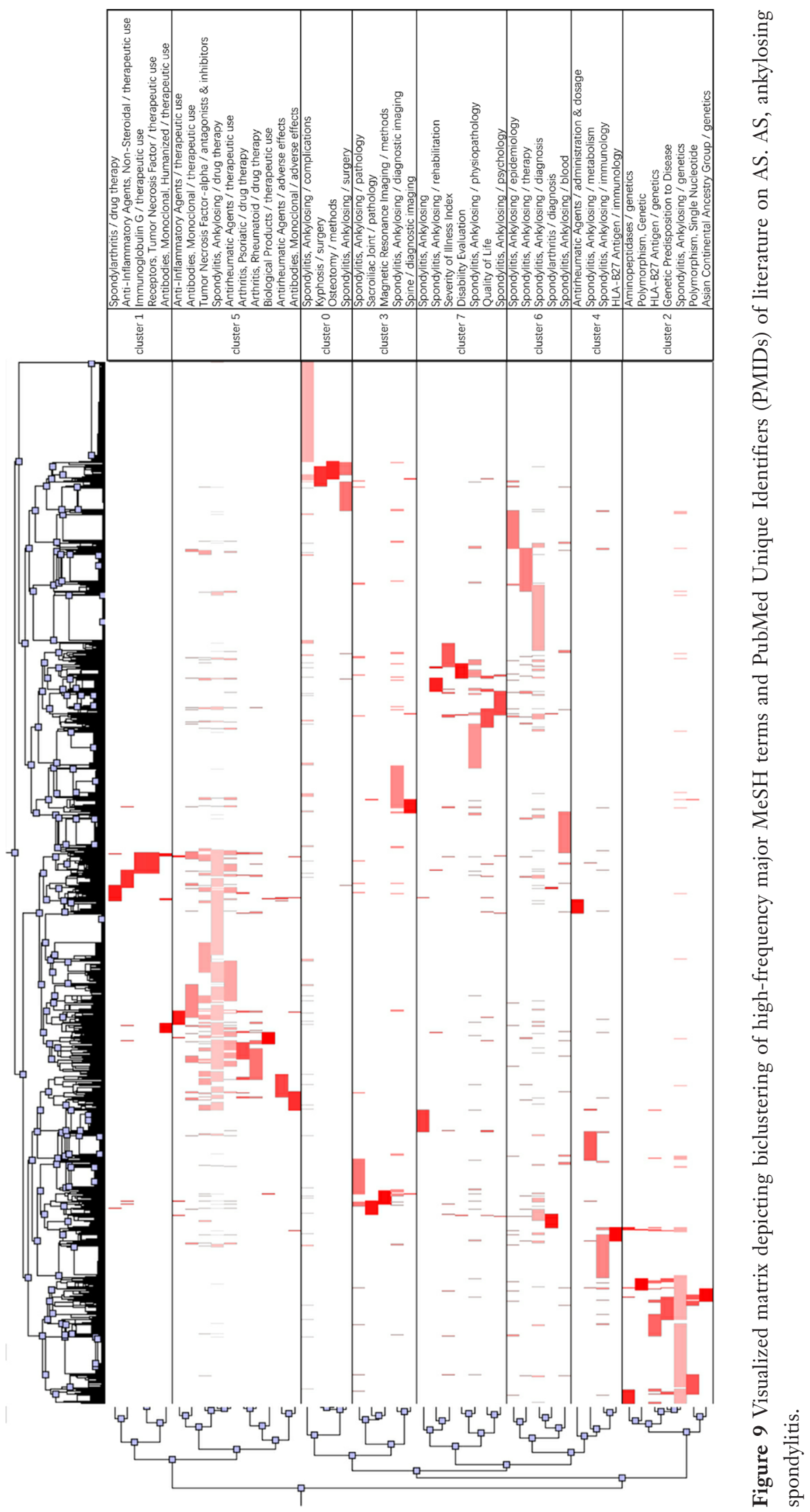


year, and the amount of scientific literature in related fields increases dramatically, making it difficult to keep up to date with the latest research in real time. For this reason, bibliometrics has become an important method of analyzing and displaying the developing trends in disease research. In this study, we found an increasing trend in the literature on AS over the 10 years between 2009 and 2018, and found 8 hotspots in AS research.

Cluster 0 relates to the surgical treatment of AS. As the disease progresses, severe AS can cause complications, such as visceral compression and impaired respiratory function. Surgery is necessary to correct the deformity to reduce symptoms and prevent serious complications. A study by Fu et al. demonstrated that pedicle subtraction osteotomy can improve pulmonary function in patients with AS kyphosis (13). A previous study also showed that corrective osteotomy is an effective surgical strategy for treating AS with kyphosis deformity (14). There are several basic osteotomy strategies, among which Zheng et al. suggested that for severe thoracolumbar kyphotic deformity, interrupted 2-level spinal osteotomy is the most effective (15). Determining the exact surgical correction angle is also important. A study by Song et al. provided a new method for calculating the precise angle required for spinal osteotomy, which can provide accurate and replicable calculations for AS correction (16). Due to the pathological characteristics of AS, AS patients are extremely susceptible to spinal fractures, which often lead to severe consequences. Given that AS is often accompanied by damage to other organs throughout the body, especially the respiratory organs, there can be many surgical complications and risks, leading to high mortality. Early literature in the field recommended conservative treatment. However, in recent years, with the continuous advancement of anesthesia technology and surgical techniques, a growing body of evidence suggests that surgical treatment can better stabilize the spine. Furthermore, surgery can directly relieve nerve compression and be more effective in avoiding complications caused by long-term traction and external fixation. Therefore, for patients with AS combined with spinal fractures, as long as the patient's physical condition allows, surgical treatment is feasible. However, for patients with certain comorbidities, choosing the appropriate surgical method is extremely important. Therefore, the classification of AS spinal fractures and the choice of fixation orthopedics are hotspots for future AS treatment.

Cluster 1 relates to TNF inhibitors as a treatment for AS. TNF inhibitors are the first biologics used to treat AS and are suitable for all stages of AS, especially for patients who have failed NSAIDS treatment or who cannot tolerate the side effects of NSAIDs. Not only can TNF inhibitors alleviate peripheral inflammation, but they can reduce pain by acting on the central nervous system (17) and can also inhibit the radiological progress of the spine (18). Furthermore, long-term TNF inhibitor treatment can slow down the development of new lesions, especially when treatment is initiated at the early stages of the disease. Since TNF inhibitors have demonstrated efficacy in the treatment of AS, future research should continue to examine the role of TNF inhibitors across the disease course of AS, and explore how to increase their sensitivity.

Cluster 2 relates to the correlation between the ERAP1 polymorphism and AS. ERAP1, unlike HLA-B27, is a non-major histocompatibility complex $(M H C)$ gene, located on chromosome $5 \mathrm{q} 15$, which has been associated with AS (19). ERAP1 can trim peptides to the optimal length for class I HLA presentation for recognition by immune cells. ERAP1 single nucleotide polymorphisms (SNPs) affect ERAP1 enzymatic properties, further affecting peptide presentation by HLA-B27 molecules. Because the frequency of alleles is not the same between different populations, the correlation between the ERAP1 polymorphism and AS is also different. Lee et al. and Zhang et al. have separately revealed that polymorphisms of ERAP1 are associated with AS susceptibility in Europeans and Beijing Han (20,21). ERAP1 gene variants have also been shown to be associated with HLA-B27 positive spondyloarthritis in Romania (22). The discovery of ERAP1 compensates for AS pathogenesis that HLA-B27 cannot fully explain. Since ERAP1 polymorphisms are associated with AS in a variety of populations, further studies on associations in specific populations are needed to determine whether ERAP1 polymorphisms are related to disease severity.

Cluster 3 relates to MRI diagnosis of AS. Imaging plays an important role in diagnosing AS. MRI demonstrating sacroiliitis has been included as an effective imaging criteria for AS by ASAS for the first time (23). MRI can detect active and structural changes more sensitively several years before conventional radiography, making it an ideal imaging method for the early diagnosis of axial spondyloarthritis (SpA) or AS (24). Akar et al. also revealed that a positive MRI result was an important risk factor for radioactive sacroiliitis (25), which may progress into AS. An MRI can significantly increase doctors' confidence in diagnosing axial SpA, which was shown to cause up to $40 \%$ 
of people to change their treatment plan and start using biological agents (26). In conclusion, using MRI as early as possible is essential in helping patients to receive anti-TNF treatment early. Researchers should also focus more on the application value of MRI compared to traditional imaging in AS diagnosis, and explore more accurate MRI diagnostic criteria.

Cluster 4 relates to the HLA-B27 pathogenesis of AS. The human leukocyte antigen class I gene HLA-B27 has a strong correlation with AS. Over $90 \%$ of AS patients carry the HLA-B27 gene, while the proportion of HLA-B27positive healthy individuals is less than $10 \%$ (27). Accorinti et al. confirmed that there was a strong association between HLA-B27, uveitis and AS. Normally, uveitis precedes the onset of rheumatism (28), which suggests that HLA-B27 has a significant correlation with AS. In recent years, the newly discovered ERAP1 and ERAP2 have filled the gap in the pathogenesis of AS. B27 peptidome formation is a key event in AS. Martín-Esteban et al. suggested that the HLA-B27 peptidome in AS pathogenesis can be affected by different ERAP1/ERAP2 phenotypes (29). Overall, although the association between HLA-B27 and AS has long been demonstrated, the exact role of HLA-B27 in the onset of AS is still elusive. In the future, further exploration into the role of HLA-B27 and its association with non-MHC factors like ERAP are needed to more comprehensively understand AS pathogenesis, which will be the largest research hotspot in AS.

Cluster 5 relates to certain TNF inhibitors as a firstline treatment for AS, and their efficacy and safety. There are five common TNF inhibitors for AS: infliximab, adalimumab, golimumab, etanercept, and certolizumab. The first three are full-length monoclonal antibodies, etanercept is a soluble fusion protein, and certolizumab is a humanized fragment antigen-binding fragment. Although they are all TNF inhibitor drugs, they are not the same in terms of drug safety and survival rate, and their efficacy and application are also different. Hence, when one of the drugs is not effective, it is usually replaced with another drug for treatment. This was confirmed by Rudwaleit et al., who demonstrated that switching to adalimumab after previous TNF antagonist treatment could improve the AS disease status. Furthermore, the safety profile was the same as that of patients who were anti-TNF treatment naive or treated with adalimumab alone (30). Kay et al. also assessed the 5-year golimumab safety profile, revealing that subcutaneous golimumab safety at year 5 was consistent with the previously reported year 3 as well as with other
TNF antagonist treatments (31). Favalli et al. compared the real-world 10-year retention rate of first-line anti-TNF drugs and withdrawal rates between adult and juvenile patients, demonstrating that etanercept showed the highest drug survival in an adult-onset population and infliximab the lowest in a juvenile-onset population (32). Due to the diversity of drugs and disease populations, more clinical trials are required to further clarify the safety and efficacy of each TNF antagonist.

Cluster 6 relates to the early diagnosis and therapy of AS. Axial spondyloarthritis (axSpA) includes non-radiological axSpA (nraxSpA) and radiological axSpA (namely, AS). Since patients with nraxSpA have similar clinical characteristics to those with confirmed AS, Rumyantseva et al. proposed that the former can be imagined as the early stage of AS (33). Due to different clinical manifestations and limited knowledge among general practitioners (GPs), axSpA is often diagnosed with a delay (34), which may lead to a more severe prognosis. Therefore, in order to diagnose AS early, educating GPs is important (35). Early identification of patients who may suffer from axSpA, along with effective treatment, can improve the functional status and quality of life for patients and may inhibit disease progression.

Cluster 7 relates to the rehabilitation treatment of AS. Researchers have demonstrated that comprehensive rehabilitation is beneficial for improving the quality of life of AS patients (36). Therefore, an effective method for assessing patient status is of great importance. Ankylosing spondylitis Quality of Life (EASi-QoL) is more effective than other QoL measures (37), and includes four aspects: physical function (PF), disease activity (DA), emotional well-being (EWB) and social participation (SP). Among these, $\mathrm{PF}$ and $\mathrm{DA}$ are the main factors that determine the patient's physical health (38). Structured education also has a positive effect on patient rehabilitation (39). Therefore, the participation of AS patients in rehabilitation and education is of vital importance.

\section{Conclusions}

Our study identified eight research hotspots in the field of AS, predicting surgical treatment and etiology as the main research trends in the future. The classification of spinal fractures in AS, the selection of corresponding internal fixation and osteotomy methods, and postoperative efficacy need to be further studied. Furthermore, the roles of HLA-B27 and ERAP in the pathogenesis of AS remain unclear, which provides new directions and ideas for future research. 


\section{Acknowledgments}

Thanks also to AME Editing Service who worked for us to improve the English language.

Funding: We are grateful to the funds for supporting this study, including Natural Science Foundation of Liao Ning (No. 2019-BS-294) and Construction of Clinical Medical Research Center of Orthopaedics and Sports Rehabilitation Diseases in Liaoning Province (No. 2019416030). This work was supported by Natural Science Foundation of Liao Ning (No. 2019-BS-294); Construction of Clinical Medical Research Center of Orthopaedics and Sports Rehabilitation Diseases in Liaoning Province (No. 2019416030).

\section{Footnote}

Conflicts of Interest: All authors have completed the ICMJE uniform disclosure form (available at http://dx.doi. org/10.21037/atm-20-1259). The authors have no conflicts of interest to declare.

Ethical Statement: The authors are accountable for all aspects of the work in ensuring that questions related to the accuracy or integrity of any part of the work are appropriately investigated and resolved. Ethical approval is not required because the research didn't involve human experiments.

Open Access Statement: This is an Open Access article distributed in accordance with the Creative Commons Attribution-NonCommercial-NoDerivs 4.0 International License (CC BY-NC-ND 4.0), which permits the noncommercial replication and distribution of the article with the strict proviso that no changes or edits are made and the original work is properly cited (including links to both the formal publication through the relevant DOI and the license). See: https://creativecommons.org/licenses/by-nc-nd/4.0/.

\section{References}

1. Cortes A, Hadler J, Pointon JP, et al. Identification of multiple risk variants for ankylosing spondylitis through high-density genotyping of immune-related loci. Nat Genet 2013;45:730-8.

2. Sieper J, Poddubnyy D. Axial spondyloarthritis. Lancet 2017;390:73-84.

3. Brown MA, Kennedy LG, MacGregor AJ, et al. Susceptibility to ankylosing spondylitis in twins: the role of genes, HLA, and the environment. Arthritis Rheum
1997;40:1823-8.

4. Baeten D, Sieper J, Braun J, et al. Secukinumab, an Interleukin-17A Inhibitor, in Ankylosing Spondylitis. N Engl J Med 2015;373:2534-48.

5. Yan XJ, Dozmorov I, Li W, et al. Identification of outcome-correlated cytokine clusters in chronic lymphocytic leukemia. Blood 2011;118:5201-10.

6. Fiannaca A, La Rosa M, La Paglia L, et al. Analysis of miRNA expression profiles in breast cancer using biclustering. BMC Bioinformatics 2015;16 Suppl 4:S7.

7. Zhou S, Tao Z, Zhu Y, et al. Mapping theme trends and recognizing hot spots in postmenopausal osteoporosis research: a bibliometric analysis. PeerJ 2019;7:e8145.

8. Li F, Li M, Guan P, et al. Mapping Publication Trends and Identifying Hot Spots of Research on Internet Health Information Seeking Behavior: A Quantitative and Co-Word Biclustering Analysis. J Med Internet Res 2015;17:e81.

9. Lei C, Wei L, Lei Y, et al. Development of a Text Mining System Based on the Co-occurrence of Bibliographic Items in Literature Databases. New Technology of Library and Information Service 2008;8:70-5.

10. Chen CJJotAfIS, Technology. CiteSpace II: Detecting and visualizing emerging trends and transient patterns in scientific literature. Available online: https://onlinelibrary. wiley.com/doi/abs/10.1002/asi.20317

11. Chen C, Ibekwe-Sanjuan F, Hou J. The structure and dynamics of cocitation clusters: A multipleperspective cocitation analysis. J Am Soc Inf Sci Technol 2010;61:1386-409.

12. Nishiyama K, Hirai K. The melatonin agonist ramelteon induces duration-dependent clock gene expression through cAMP signaling in pancreatic INS-1 $\beta$-cells. PLoS One 2014;9:e102073.

13. Fu J, Zhang G, Zhang Y, et al. Pulmonary function improvement in patients with ankylosing spondylitis kyphosis after pedicle subtraction osteotomy. Spine (Phila Pa 1976) 2014;39:E1116-22.

14. Kim KT, Park DH, Lee SH, et al. Results of Corrective Osteotomy and Treatment Strategy for Ankylosing Spondylitis with Kyphotic Deformity. Clin Orthop Surg 2015;7:330-6.

15. Zheng GQ, Song K, Zhang YG, et al. Two-level spinal osteotomy for severe thoracolumbar kyphosis in ankylosing spondylitis. Experience with 48 patients. Spine (Phila Pa 1976) 2014;39:1055-8.

16. Song K, Zheng G, Zhang Y, et al. A New Method for Calculating the Exact Angle Required for Spinal 
Osteotomy. Spine 2013;38:E616-20.

17. Hess A, Axmann R, Rech J, et al. Blockade of TNF- $\alpha$ rapidly inhibits pain responses in the central nervous system. Proc Natl Acad Sci U S A 2011;108:3731-6.

18. Molnar C, Scherer A, Baraliakos X, et al. TNF blockers inhibit spinal radiographic progression in ankylosing spondylitis by reducing disease activity: results from the Swiss Clinical Quality Management cohort. Ann Rheum Dis 2018;77:63-9.

19. Burton PR, Clayton DG, Cardon LR, et al. Association scan of 14,500 nonsynonymous SNPs in four diseases identifies autoimmunity variants. Nat Genet 2007;39:1329-37.

20. Lee YH, Choi SJ, Ji JD, et al. Associations between ERAP1 polymorphisms and ankylosing spondylitis susceptibility: a meta-analysis. Inflamm Res 2011;60:999-1003.

21. Zhang Z, Dai D, Yu K, et al. Association of HLA-B27 and ERAP1 with ankylosing spondylitis susceptibility in Beijing Han Chinese. Tissue Antigens 2014;83:324-9.

22. Cherciu M, Popa LO, Bojinca M, et al. Functional variants ofERAP1gene are associated with HLA-B27 positive spondyloarthritis. Tissue Antigens 2013;82:192-6.

23. Rudwaleit $M$, van der Heijde D, Landewé R, et al. The development of Assessment of SpondyloArthritis international Society classification criteria for axial spondyloarthritis (part II): validation and final selection. Ann Rheum Dis 2009;68:777-83.

24. Hermann KG, Bollow M. Magnetic resonance imaging of sacroiliitis in patients with spondyloarthritis: correlation with anatomy and histology. Rofo 2014;186:230-7.

25. Akar S, Isik S, Birlik B, et al. Baseline sacroiliac joint magnetic resonance imaging abnormalities and male sex predict the development of radiographic sacroiliitis. Clin Rheumatol 2013;32:1511-7.

26. Carmona R, Harish S, Linda DD, et al. MR imaging of the spine and sacroiliac joints for spondyloarthritis: influence on clinical diagnostic confidence and patient management. Radiology 2013;269:208-15.

27. Tam LS, Gu J, Yu D. Pathogenesis of ankylosing spondylitis. Nat Rev Rheumatol 2010;6:399-405.

28. Accorinti M, Iannetti L, Liverani M, et al. Clinical features and prognosis of HLA B27-associated acute anterior uveitis in an Italian patient population. Ocul Immunol Inflamm 2010;18:91-6.

29. Martín-Esteban A, Sanz-Bravo A, Guasp P, et al. Separate effects of the ankylosing spondylitis associated ERAP1 and ERAP2 aminopeptidases determine the influence of their combined phenotype on the HLA-B*27 peptidome. J Autoimmun 2017;79:28-38.
30. Rudwaleit M, Van den Bosch F, Kron M, et al. Effectiveness and safety of adalimumab in patients with ankylosing spondylitis or psoriatic arthritis and history of anti-tumor necrosis factor therapy. Arthritis Res Ther 2010;12:R117.

31. Kay J, Fleischmann R, Keystone E, et al. Five-year Safety Data from 5 Clinical Trials of Subcutaneous Golimumab in Patients with Rheumatoid Arthritis, Psoriatic Arthritis, and Ankylosing Spondylitis. J Rheumatol 2016;43:2120-30.

32. Favalli EG, Pontikaki I, Becciolini A, et al. Real-life 10-year retention rate of first-line anti-TNF drugs for inflammatory arthritides in adult- and juvenile-onset populations: similarities and differences. Clin Rheumatol 2017;36:1747-55.

33. Rumyantseva DG, Dubinina TV, Demina AB, et al. Ankylosing spondylitis and non-radiographic axial spondyloarthritis: Two stages of disease? Ter Arkh 2017;89:33-7.

34. Poddubnyy D, Vahldiek J, Spiller I, et al. Evaluation of 2 screening strategies for early identification of patients with axial spondyloarthritis in primary care. J Rheumatol 2011;38:2452-60.

35. van Onna M, Gorter S, van Meerendonk A, et al. General practitioners' perceptions of their ability to identify and refer patients with suspected axial spondyloarthritis: a qualitative study. J Rheumatol 2014;41:897-901.

36. Księżopolska-Orłowska K, Pacholec A, Bugajska J, et al. The Effect of Comprehensive Musculoskeletal Rehabilitation on Clinical Status of Ankylosing Spondylitis Patients. Ortop Traumatol Rehabil 2016;18:41-52.

37. Packham JC, Jordan KP, Haywood KL, et al. Evaluation of Ankylosing Spondylitis Quality of Life questionnaire: responsiveness of a new patient-reported outcome measure. Rheumatology (Oxford) 2012;51:707-14.

38. Ariza-Ariza R, Hernández-Cruz B, López-Antequera G, et al. Variables related to utility in patients with ankylosing spondylitis. Clin Rheumatol 2009;28:207-11.

39. Kasapoglu Aksoy M, Birtane M, Taştekin N, et al. The Effectiveness of Structured Group Education on Ankylosing Spondylitis Patients. J Clin Rheumatol 2017;23:138-43.

Cite this article as: Liang M, Meng Y, Zhou S, Tao Z, Tao L. Research hotspots and trends analysis of ankylosing spondylitis: a bibliometric and scientometric analysis from 2009 to 2018. Ann Transl Med 2020;8(21):1445. doi: 10.21037/atm-20-1259 